increased motor vehicle crash rate. ${ }^{14}$ Mulgrew and associates ${ }^{15}$ compared 3year objective motor vehicle crash rates in 783 patients with suspected OSA and 783 matched control subjects. There were 252 crashes in the patients and 123 crashes in the control subjects. No dose-response effect was observed between the crash rate and OSA severity except in the subgroup of patients in crashes involving personal injury. Furthermore, there was no relationship between crash rate and subjective daytime sleepiness. These findings emphasise the importance of treating all patients with OSA. George ${ }^{16}$ performed a study comparing motor vehicle crash rates for 3 years before and after CPAP treatment in 210 patients with OSA versus 210 matched controls using objective motor vehicle crash records. The crash rate was about three times higher than for control subjects before CPAP treatment and was similar to control subjects after treatment.

Although there is now convincing evidence that CPAP is an effective treatment for OSA, it has still been difficult to convince some healthcare funding agencies to provide funding. Until recently, there were limited data concerning the cost-effectiveness of CPAP treatment. Guest and colleagues ${ }^{17}$ constructed a Markov model including cardiovascular events, motor vehicle crashes and treatment compliance to estimate the cost-effectiveness of CPAP in the management of patients with severe OSA compared with no treatment from the perspective of the UK's National Health Service (NHS). According to the model, $57 \%$ of untreated patients were expected to be alive at the end of 14 years compared with $72 \%$ of patients treated with CPAP. Untreated patients are expected to cost the NHS $£ 10645$ per patient over 14 years compared with $£ 9672$ per CPAP-treated patient. Treatment with CPAP for a period of 1 year was not a cost-effective option since the cost per quality-adjusted life year gained was $>£ 20000$, but after 2 years of treatment the cost per quality-adjusted life year gained was $£ 10000$ or less and, after 13 years of treatment, CPAP was more effective than no treatment for less cost.

Over the last decade patients, physicians and healthcare funding agencies have been waking up to the importance of sleep-disordered breathing. The evidence which independently links OSA to cardiovascular risk factors and motor vehicle crashes is now compelling. CPAP treatment has been shown to decrease some cardiovascular risk factors and motor vehicle crashes. Preliminary results of a large long-term randomised controlled trial indicate that CPAP reduces cardiovascular events and hypertension in patients who comply with treatment. CPAP has been established as a costeffective treatment and many countries now recommend that it should be made available to patients with symptomatic OSA. ${ }^{18} 19$

\section{Competing interests None.}

Provenance and peer review Commissioned; not externally peer reviewed.

Thorax 2010;65:762-763.

doi:10.1136/thx.2010.144931

\section{REFERENCES}

1. Wright J, Johns R, Watt I, et al. Health effects of obstructive sleep apnoea and the effectiveness of continuous positive airway pressure: a systematic review of the research evidence. BMJ 1997:314:851-60.

2. Fleetham JA. A wake up call for sleep disordered breathing. BMJ 1997;314:839-40.

3. Hui DS, To KW, Ko FW, et al. Nasal CPAP reduces systemic blood pressure in patients with obstructive sleep apnoea and mild sleepiness. Thorax 2006;61:1083-90.

4. Robinson GV, Langford BA, Smith DM, et al. Predictors of blood pressure fall with continuous positive airway pressure (CPAP) treatment of obstructive sleep apnoea (OSA). Thorax 2008:63:855-9.
5. West SD, Nicoll DJ, Stradling JR. Prevalence of obstructive sleep apnoea in men with type 2 diabetes. Thorax 2006;61:945-50.

6. Ronksley PE, Hemmelgarn BR, Heitman SJ, et al. Obstructive sleep apnoea is associated with diabetes in sleepy subjects. Thorax 2009;64:834-9.

7. Ip M. Obstructive sleep apnoea, insulin resistance and sleepiness. Thorax 2008;63:939-40.

8. Barceló A, Barbé $F$, de la Peña $M$, et al. Insulin resistance and daytime sleepiness in patients with sleep apnoea. Thorax 2008;63:946-50.

9. West SD, Nicoll DJ, Wallace TM, et al. Effect of CPAP on insulin resistance and $\mathrm{HbA} 1 \mathrm{c}$ in men with obstructive sleep apnoea and type 2 diabetes. Thorax 2007:62:969-74.

10. Cross MD, Mills NL, Al-Abri M, et al. Continuous positive airway pressure improves vascular function in obstructive sleep apnoea/hypopnoea syndrome: a randomised controlled trial. Thorax 2008;63:578-83.

11. Kohler M, Ayers L, Pepperell JCT, et al. Effects of continuous positive airway pressure on systemic inflammation in patients with moderate to severe obstructive sleep apnoea: a randomised controlled trial. Thorax 2009;64:67-73.

12. Ayas NT, Mancini GBJ, Fleetham JA. Does CPAP delay the development of cardiovascular disease in patients with obstructive sleep apnoea hypopnoea? Thorax 2006;61:459-60.

13. Barbé $\mathbf{F}$, Duran-Cantolla J, Carmona $\mathrm{C}$, et al. Effect of CPAP treatment on the incidence of cardiovascular events and hypertension in non-sleepy OSAS patients. A long-term RCT. Am J Respir Crit Care Med 2010:181:A5559.

14. Stradling J. Driving and obstructive sleep apnoea. Thorax 2008;63:481-3.

15. Mulgrew AT, Nasvadi G, Butt A, et al. Risk and severity of motor vehicle crashes in patients with obstructive sleep apnea hypopnea. Thorax 2008;63:536-41.

16. George CF. Reduction in motor vehicle collisions following treatment of sleep apnoea with nasal CPAP. Thorax 2001:56:508-12.

17. Guest JF, Helter MT, Morga A, et al. Costeffectiveness of using continuous positive airway pressure in the treatment of severe obstructive sleep apnoea/hypopnoea syndrome in the UK. Thorax 2008;63:860-5

18. National Institute for Health and Clinical

Excellence. Continuous positive airway pressure for the treatment of obstructive sleep apnoea/hypopnoea syndrome. 2007. http://www.nice.org.uk/guidance/ index.jsp?action $=$ bylD\&0 $=11944$.

19. Centers for Medicare and Medicaid Services. Decision memo for continuous positive airway pressure (CPAP) therapy for obstructive sleep apnea (OSA) (CAG-00093R2). https://www.cms.hhs.gov/ $\mathrm{mcd} /$ viewdecisionmemo.asp?

from2 $=$ viewdecisionmemo.asp\&id $=204 \varepsilon$

\title{
Travelling in time with COPD
}

\section{J R Hurst, ${ }^{1}$ P M A Calverley ${ }^{2}$}

${ }^{1}$ Academic Unit of Respiratory Medicine, UCL Medical School, London, UK; ${ }^{2}$ Clinical Science Centre, University Hospital Aintree, Liverpool, UK

Correspondence to J R Hurst, Academic Unit of Respiratory Medicine, UCL Medical School, London, UK; j.hurst@medsch.ucl.ac.uk
In the last 8 years the $\mathrm{FEV}_{1}$ (forced expiratory volume in $1 \mathrm{~s}$ ) of a 'typical' patient with chronic obstructive pulmonary disease (COPD) has fallen by $\sim 400 \mathrm{ml}$. However, the knowledge of those caring for this hypothetical patient has grown rapidly in this same period and Thorax has played a vital role in this change of fortune. In 2003 there were 1698 citations to COPD articles in PubMed, compared with 1494 in the first 6 months of 2010 alone, a remarkable growth in the interest in and perhaps quality of research in this field.

Many themes have been considered in this last 8 years, not least how to diagnose the disease. Swanney et $a l^{1}$ defined population norms for the lower limit of normal of the $\mathrm{FEV}_{1} /$ forced vital capacity (FVC) 
ratio to avoid overdiagnosis of airflow obstruction in the elderly. However, not all were convinced, especially when there appeared to be no difference in mortality when the definition was varied in this way. $^{2}$ The absence of bronchodilator reversibility proved to be an unreliable defining feature in $\mathrm{COPD},{ }^{3}$ and the treatment guidelines changed to reflect this new research. ${ }^{4}$ Classifying patients with GOLD (global initiative for chronic obstructive lung disease) stage 1 disease (reduced $\mathrm{FEV}_{1} / \mathrm{FVC}$ but $\mathrm{FEV}_{1}>80 \%$ predicted) proved difficult as some patients were not reproducibly obstructed. However, those with symptoms did show more rapid decline in lung function, ${ }^{5}$ were more likely to have previous bronchitic symptoms ${ }^{6}$ and responded physiologically to inhaled bronchodilators. ${ }^{7}$ So, contrary to earlier views, GOLD stage 1 may be a clinically relevant entity after all.

COPD is normally thought of as a 'smokers' illness', and some have argued that it should only be diagnosed in smokers. Powerful arguments against this view have come from the elegant laboratory and epidemiological studies from South China where a clear relationship between symptomatic airflow limitation and biomass fuel exposure has been demonstrated, $^{8}$ not to mention the clear associations between COPD and occupation reviewed by Blanc and colleagues. ${ }^{9}$ Moreover, early life events such as parental asthma, maternal smoking and respiratory infections play an unexpectedly large part in determining who will subsequently lose lung function. ${ }^{10}$ Ideally we would be able just to take blood, and a serum biomarker would give us some clinical certainty. A comprehensive review by Gan et al showed that there is growing evidence for systemic inflammation in COPD but at the patient level there is too much variability in any of the potential biomarkers of inflammation to make them suitable for clinical decision making. ${ }^{11}$

Sometimes you cannot see what is in front of you and it is embarrassing to realise just how many co-morbid conditions affect our patients with COPD, as shown in a large Italian study of people undergoing pulmonary rehabilitation. ${ }^{12}$ These are not just chance occurrences. Mills et al showed that increased arterial stiffness and raised blood pressure were associated with COPD independently of age and smoking. ${ }^{13}$ Patel et al reported an association between wrinkling as a surrogate of elastin destruction and COPD, ${ }^{14}$ while the Edinburgh group subsequently completed the argument by relating arte- rial stiffness to CT-defined emphysema. These observations add to the growing evidence that COPD is best seen as a disease of accelerated ageing, a fruitful new area for research in the coming years. Clearly COPD is not just a lung disease but is, at the least, a marker for other important conditions. This helps explain the elegant data from the TORCH study which showed that many patients with clinically significant COPD die from non-respiratory causes and especially cardiovascular disease. ${ }^{15}$

Respiratory physiology staged a comeback as new methods allowed us to ask new clinically relevant questions. For the first time we could measure chest wall movement directly using opto-electronic plethysmography. This showed that although the lungs may hyperinflate as exercise begins the chest wall does not always change in parallel and, when patients activate their abdominal muscles in the face of airflow obstruction, they may stop sooner than expected. ${ }^{16}$ Similar techniques showed that the timing of hyperinflation varied between patients and that rehabilitation was associated with less chest wall overinflation during exercise. ${ }^{17}$ Non-invasive measurements of lung mechanics by forced oscillation methods identified significant falls in inspiratory resistance and lung volume as COPD exacerbations resolved ${ }^{18}$ while measurements of quadriceps muscle strength became the latest independent prognostic marker for patients with more severe COPD. ${ }^{19}$

Exacerbations of COPD are now recognised as key events in the natural history of the disease with exacerbating patients having not only a worse health status but a worse prognosis. ${ }^{20}$ Infection, both viral and bacterial, is accepted as a key trigger to these events, but we now have evidence that gastro-oesophageal reflux ${ }^{21}$ and changes in atmospheric air pollution ${ }^{22}$ also precipitate these episodes. Old treatments may be more valuable than we thought. Roede and colleagues reported a provocative pharmaco-epidemiological study suggesting that the addition of antibiotics to steroids at exacerbation prolonged time not only to the next exacerbation, but also to the exacerbation after that. ${ }^{23}$ Intravenous xanthines fared less well as they failed to influence the outcome of hospitalised patients in the largest randomised controlled trial to date of this treatment. ${ }^{24}$

There has been much debate about the use of long-acting bronchodilators with and without inhaled corticosteroids in the management of stable disease, and Thorax has published important papers from both sides of this debate. As a result, there is now a consensus on when and how these drugs should be used, and this has been recently reviewed in the limited update of the National Institute for Health and Clinical Excellence (NICE) guidance. It is also evident that we need new treatment approaches to make further progress. Theophyllines have been available for years, but the suggestion from Cosio and colleagues in 2009 that they may reduce the apparent corticosteroid insensitivity observed in COPD has led to a resurgence of interest in these drugs - and at low dose too. ${ }^{25}$ Non-drug treatment has been evaluated with mixed results. Short-burst oxygen therapy to relieve breathlessness has proven ineffective physiologically, ${ }^{26}$ although the suspicion lingers that occasional patients may benefit to a minor degree. $^{27}$ Eight years ago non-invasive ventilation at exacerbation was becoming widely available, and McEvoy and colleagues have recently conducted a challenging trial in patients with stable hypercapnia who lived longer with this treatment but felt worse, ${ }^{28}$ making its routine use at present an unattractive prospect.

The last 8 years has shown us that we used to frequently miss the diagnosis of COPD even in those with severe airflow limitation $^{29}$ and that our healthcare system often failed them when they were acutely ill. ${ }^{30}$ However, recent survey data from the Royal College of Physicians show that we are doing better and encouragingly our patients seem to be living longer. ${ }^{31}$ The past is a foreign country, they do things differently there as LP Hartley said, and this is just as true for COPD as for any area of life. Building on what we have learnt using new tools and new treatment approaches sometimes applied to old drugs but often to the new agents just entering clinical trials is sure to drive forward our understanding of the causes, consequences and impacts of COPD. Often the biggest effect comes from a change in how we deliver care rather than the components of the care we deliver. Changing how the patient behaves can have dramatic effects on their outcome. Perhaps the most surprising paper of the last 8 years was the report from the TORCH study showing that patients who took their treatment had substantial and highly significant differences in hospitalisation and death rates compared with those who did not-even when randomised to placebo! ${ }^{32}$ 
Whatever the results of these new studies, we are confident that the best of them will be published in Thorax, which will remain at the heart of respiratory research in the decade ahead.

Competing interests None.

Provenance and peer review Commissioned; not externally peer reviewed.

Thorax 2010;65:763-765

doi:10.1136/thx.2010.146811

\section{REFERENCES}

1. Swanney MP, Ruppel G, Enright PL, et al. Using the lower limit of normal for the FEV1/FVC ratio reduces the misclassification of airway obstruction. Thorax 2008;63:1046-51.

2. Mannino DM, Reichert MM, Davis KJ. Lung function decline and outcomes in an adult population. $\mathrm{Am} \mathrm{J}$ Respir Crit Care Med 2006:173:985-90.

3. Calverley PM, Burge PS, Spencer S, et al. Bronchodilator reversibility testing in chronic obstructive pulmonary disease. Thorax 2003;58:659-64.

4. Chronic obstructive pulmonary disease. National clinical guideline on management of chronic obstructive pulmonary disease in adults in primary and secondary care. Thorax 2004;59/Suppl 1):1-232.

5. Bridevaux P0, Gerbase MW, Probst-Hensch NM, et al. Long-term decline in lung function, utilisation of care and quality of life in modified GOLD stage 1 COPD. Thorax 2008;63:768-74.

6. Guerra S, Sherrill DL, Venker C, et al. Chronic bronchitis before age 50 years predicts incident airflow limitation and mortality risk. Thorax 2009;64:894-900

7. O'Donnell DE, Laveneziana P, Ora J, et al. Evaluation of acute bronchodilator reversibility in patients with symptoms of GOLD stage I COPD. Thorax 2009;64:216-23.

8. Liu S, Zhou $Y$, Wang $X$, et al. Biomass fuels are the probable risk factor for chronic obstructive pulmonary disease in rural South China. Thorax 2007;62:889-97.

9. Blanc PD, Iribarren C, Trupin L, et al. Occupational exposures and the risk of COPD: dusty trades revisited. Thorax 2009;64:6-12.
10. Svanes C, Sunyer J, Plana E, et al. Early life origins of chronic obstructive pulmonary disease. Thorax 2010;65:14-20.

11. Gan W0, Man SF, Senthilselvan A, et al. Association between chronic obstructive pulmonary disease and systemic inflammation: a systematic review and a meta-analysis. Thorax 2004;59:574-80.

12. Crisafulli E, Costi S, Luppi F, et al. Role of comorbidities in a cohort of patients with COPD undergoing pulmonary rehabilitation. Thorax 2008;63:487-92.

13. Mills NL, Miller JJ, Anand A, et al. Increased arterial stiffness in patients with chronic obstructive pulmonary disease: a mechanism for increased cardiovascular risk. Thorax 2008;63:306-11.

14. Patel BD, Loo WJ, Tasker AD, et al. Smoking related COPD and facial wrinkling: is there a common susceptibility? Thorax 2006;61:568-71.

15. McGarvey LP, John M, Anderson JA, et al. Ascertainment of cause-specific mortality in COPD operations of the TORCH Clinical Endpoint Committee. Thorax 2007:62:411-15.

16. Aliverti A, Stevenson N, Dellaca RL, et al. Regional chest wall volumes during exercise in chronic obstructive pulmonary disease. Thorax 2004;59:210-16.

17. Georgiadou 0, Vogiatzis I, Stratakos G, et al. Effects of rehabilitation on chest wall volume regulation during exercise in COPD patients. Eur Respir $J$ 2007;29:284-91.

18. Johnson MK, Birch M, Carter R, et al. Measurement of physiological recovery from exacerbation of chronic obstructive pulmonary disease using within-breath forced oscillometry. Thorax 2007;62:299-306

19. Swallow EB, Reyes D, Hopkinson NS, et al. Quadriceps strength predicts mortality in patients with moderate to severe chronic obstructive pulmonary disease. Thorax 2007:62:115-20.

20. Soler-Cataluna JJ, Martinez-Garcia MA, Roman SP, et al. Severe acute exacerbations and mortality in patients with chronic obstructive pulmonary disease. Thorax 2005;60:925-31.

21. Terada K, Muro S, Sato S, et al. Impact of gastro-oesophageal reflux disease symptoms on COPD exacerbation. Thorax 2008;63:951-5.
22. Ko FW, Tam W, Wong TW, et al. Temporal relationship between air pollutants and hospital admissions for chronic obstructive pulmonary disease in Hong Kong. Thorax 2007;62:780-5.

23. Roede BM, Bresser P, Bindels PJ, et al. Antibiotic treatment is associated with reduced risk of a subsequent exacerbation in obstructive lung disease: an historical population based cohort study. Thorax 2008;63:968-73.

24. Duffy N, Walker P, Diamantea F, et al. Intravenous aminophylline in patients admitted to hospital with exacerbations of chronic obstructive pulmonary disease: a prospective randomised controlled trial. Thorax

2005;60:713-17.

25. Cosio BG, Iglesias A, Rios A, et al. Low-dose theophylline enhances the anti-inflammatory effects of steroids during exacerbations of COPD. Thorax 2009;64:424-9.

26. Stevenson NJ, Calverley PM. Effect of oxygen on recovery from maximal exercise in patients with chronic obstructive pulmonary disease. Thorax 2004:59:668-72.

27. Nandi K, Smith AA, Crawford A, et al. Oxygen supplementation before or after submaximal exercise in patients with chronic obstructive pulmonary disease. Thorax 2003;58:670-3.

28. McEvoy RD, Pierce RJ, Hillman D, et al. Nocturnal non-invasive nasal ventilation in stable hypercapnic COPD: a randomised controlled trial. Thorax 2009;64:561-6

29. Shahab L, Jarvis MJ, Britton J, et al. Prevalence, diagnosis and relation to tobacco dependence of chronic obstructive pulmonary disease in a nationally representative population sample. Thorax 2006;61:1043-7.

30. Price LC, Lowe D, Hosker $\mathrm{H}$, et al. UK National COPD Audit 2003: impact of hospital resources and organisation of care on patient outcome following admission for COPD exacerbation. Thorax 2006;61:837-42

31. Almagro P, Salvado M, Garcia-Vidal C, et al Recent improvement in long-term survival after a COPD hospitalisation. Thorax 2010;65:298-302.

32. Vestbo J, Anderson JA, Calverley P, et al. Adherence to inhaled therapy, mortality, and hospital admission in COPD. Thorax 2009;64:939-43.

\section{Non-invasive positive pressure ventilation in patients with stable hypercapnic COPD: light at the end of the tunnel?}

\section{Bernd Schönhofer}

Correspondence to Professor Dr Bernd Schönhofer, Klinikum Oststadt-Heidehaus, Region Hannover, Abteilung Pneumologie und internistische Intensivmedizin, Podbielskistrasse 380, 30659 Hannover, Germany; bernd.schoenhofer@t-online.de
Eighteen years ago in this journal, Elliott and coworkers reported on the feasibility of non-invasive positive pressure ventilation (NPPV) to improve blood gases, total sleep time and sleep efficiency in 7 of 12 patients with stable hypercapnic chronic obstructive pulmonary disease (COPD) who continued NPPV for 1 year. ${ }^{1}$ However, a meta-analysis summarising four subsequent randomised controlled trials conducted in the 1990s clearly showed that 3 months of NPPV in patients with stable COPD did not improve lung function, gas exchange or sleep efficiency. ${ }^{2}$ Moreover, descriptive long-term follow-up of patients receiving home NPPV showed that patients with thoracic restrictive and neuromuscular disorders had a favourable long-term outcome, but not patients with COPD. ${ }^{3}$ In addition, two subsequent randomised controlled trials from the beginning of the last decade demonstrated that long-term survival did not improve when NPPV was added to long-term oxygen treatment 